\title{
Two phase randomised controlled clinical trial of postoperative oral dietary supplements in surgical patients
}

\author{
A M Keele, M J Bray, P W Emery, H D Duncan, D B A Silk
}

\begin{abstract}
Background-Previous work has shown that the administration of oral dietary supplements to patients who have undergone gastrointestinal surgery results in clinically significant short term benefits.

Aims-This study aimed firstly to reevaluate these short term effects, and secondly to establish whether there are any long term benefits.
\end{abstract}

Subjects-One hundred patients admitted for elective moderate or major gastrointestinal surgery.

Methods-In the inpatient phase, patients were randomised to receive a normal ward diet postoperatively, or the same diet supplemented with an oral dietary supplement. In the outpatient phase, patients were further randomised to receive their home diet, or their home diet supplemented with the oral dietary supplement for four months.

Results-During the inpatient phase, patients treated with oral supplements had a significantly improved nutritional intake and lost less weight $(2 \cdot 2,95 \%$ confidence interval $(95 \% \mathrm{CI}) 0.9 \mathrm{~kg})$ compared with control patients $(4.2(0 \cdot 78) \mathrm{kg}, \mathrm{p}<$ $0 \cdot 001)$. Supplemented patients maintained their hand grip strength whereas control patients showed a significant reduction in grip strength $(p<0 \cdot 01)$. Subjective levels of fatigue increased significantly above preoperative levels in control patients $(p<0.01)$ but not in the supplemented group. Twelve patients in the control group developed complications compared with four in the supplemented group $(p<0 \cdot 05)$. In the outpatient phase, supplemented patients had improved nutrient intakes but there were no significant differences in indices of nutritional status or wellbeing between the groups.

Conclusions-The prescription of oral dietary supplements to patients who have undergone gastrointestinal surgery results in clinically significant benefits. These benefits, however, are restricted to the inpatient phase.

(Gut 1997; 40: 393-399)

Keywords: oral dietary supplements, postoperative surgical patients, nutritional intake, nutritional status, complications.

The high incidence of malnutrition in hospital patients was highlighted almost 20 years ago $^{1-3}$ and recent work indicates little improvement in the situation. ${ }^{4}$ In surgical patients malnutrition increases postoperative morbidity, mortality, ${ }^{5}$ and duration and $\operatorname{cost}^{7}$ of hospital stay. Previous studies evaluating the efficacy of perioperative nutritional support have shown limited benefit. Perioperative parenteral nutrition has only been shown to benefit severely malnourished patients, ${ }^{8}$ and the routine use of feeding jejunostomies after gastrointestinal surgery cannot be justified. ${ }^{9}$ Clinically significant benefits have been seen with nasojejunal feeding after gastrointestinal surgery, ${ }^{10}$ and with simple oral dietary supplements after both orthopaedic surgery ${ }^{11}$ and gastrointestinal surgery. ${ }^{12}$ The aims of this study were twofold: (1) to re-evaluate earlier work ${ }^{12}$ showing that there are short term benefits of giving postoperative oral dietary supplements to patients undergoing gastrointestinal surgery, and (2) to establish whether there are any long term benefits of continuing supplements beyond the immediate postoperative period.

\section{Methods}

The study was conducted with the approval of Parkside district ethics committee and all patients gave informed consent. It was a prospective randomised controlled trial, comprising an inpatient and an outpatient phase.

Patients were considered for enrolment if they were adults admitted to Central Middlesex Hospital NHS Trust for elective moderate to major gastrointestinal surgery, as previously defined. ${ }^{12}$ Patients were excluded if they were to undergo laparoscopic surgery, had diabetes or overt dementia, had received preoperative enteral or parenteral nutrition, or had undergone previous abdominal radiotherapy. Patients were withdrawn if the attending surgical team, in consultation with the hospital nutrition team, determined that enteral or parenteral nutrition was indicated.

\section{Phase 1: the inpatient phase}

On admission to hospital patients were randomised to a control or treatment group. In the immediate postoperative period all patients received standard care. The study period started when the attending surgical team determined that free fluids or a light diet should be commenced, and continued until the day of hospital discharge. During the study period, control patients received the standard hospital diet. Patients in the treatment group received the standard hospital diet supplemented ad 
libitum with an oral dietary supplement (Fortisip, Nutricia, Holland), available in 200 $\mathrm{ml}$ cartons, in various flavours, providing 1.5 $\mathrm{kcal}$ and $0.05 \mathrm{~g}$ protein per $\mathrm{ml}$. Patients were encouraged to consume the supplements in small, frequent amounts, in between meals.

Patients selected their own food at meal times from the hospital multichoice menu. Soft drinks and snacks, which were readily available, were allowed as desired. Nutrient intake was assessed by daily food records from day 1 until day 7 of the study period, unless preceded by discharge. The records were kept by the study patients whenever possible, who were instructed to document intake of all food and drink, immediately after consumption, using household measures and hospital portion sizes. Portion sizes were obtained from the hospital caterers and confirmed by sample weighing. The remains of any partially drunk supplements were measured. The records were reviewed by the study dietitian and discussed with the patients to clarify intake. Energy and protein intakes were calculated using Foodbase nutrition database, ${ }^{13}$ with data for hospital dishes added. Nutritional status was assessed preoperatively, on day 3 of the study period, and on discharge. All assessments were carried out by the same observer (AK). Weight was measured on BASCH sitting scales. Percentage usual body weight (\%UBW) was calculated, where UBW was the higher of the patients' weight two or six months after admission. Height was measured with a wall mounted stadiometer and body mass index (BMI) calculated (BMI=weight $(\mathrm{kg}) /$ height $(\mathrm{m})^{2}$ ). Midarm circumference (MAC) and triceps skinfold thickness (TSF) were measured on the non-dominant arm by accepted methods $^{14}$ using a flexible steel tape and Holtain skinfold calipers. Midarm muscle circumference (MAMC) was calculated according to the formula MAMC $(\mathrm{cm})=$ MAC $(\mathrm{cm})-$ 0.3142 TSF (mm). Hand grip dynamometry was carried out with a Martin vigorimeter (Gerbrüder Martin, Germany). Patients were instructed to squeeze the bulb quickly and maximally using their non-dominant hand. Three results were recorded, allowing 10 seconds of rest between each reading, and the highest was taken as the patients' grip strength. Venous blood samples were obtained and serum albumin measured by an array rate nephelometer (Beckman Instruments UK Ltd). Nutrition risk index (NRI) was calculated according to the formula $\mathrm{NRI}=1.519$ albumin $(\mathrm{g} / \mathrm{l})+0 \cdot 417 \% \mathrm{UBW}$, (where a score of 97.5-100 indicated borderline malnutrition, 83.5-97.5 mild malnutrition, and $<83.5$ severe malnutrition). ${ }^{8}$

Subjective levels of fatigue were measured preoperatively, on study day 3, and on discharge, in a subgroup of 34 patients, with a visual analogue scale. ${ }^{15} \mathrm{~A}$ score of 1 corresponded to feeling totally fit, and a score of 10 implied total fatigue.

Patients were monitored for complications throughout the study period. Monitoring took place by daily observation of the patient, by checking their medical and nursing notes, and by liaison with the attending surgical team and nursing staff. The criteria previously described by Buzby et $a l^{16}$ were strictly adhered to for diagnosis of complications. Minor complications such as thrombophlebitis or urinary tract infections were not included.

Phase 2: the outpatient phase

Phase 2 continued for four months after discharge from hospital. On discharge patients were further randomised forming four groups (Table I).

Patients who were randomised to the treat- is ment groups for the outpatient phase were $\overrightarrow{0}$ given supplements on discharge and encouraged to take them ad libitum, in addition $\vec{\omega}$ to their normal diet. Further supplies were $\widehat{\varrho}$ collected from the hospital or delivered to their home. Assessments were performed one, two, $\overrightarrow{0}$ and four months after discharge from hospital, $\omega$ in the outpatient department or the patients' homes.

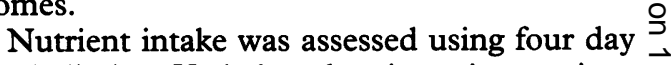
food diaries. Verbal and written instructions $\vec{z}$ were given, together with a series of photographs illustrating different portion sizes of $\frac{\hat{\sigma}}{\partial}$ commonly used foods (developed by Dunn $\vec{\theta}$ Clinical Nutrition Centre, Cambridge, England). Patients were instructed to record their intake over a weekend and two weekdays, during the week before their outpatient $\bar{\partial}$ appointment. Energy and protein intakes were calculated $^{13}$ and an average daily intake over a $\stackrel{\square}{\Phi}$ week determined.

Measurements of nutritional status were $\frac{\overline{0}}{3}$ repeated in phase 2 .

Wellbeing was assessed using the wellbeing index for surgical patients (WISP), developed for this trial by Galen Research, Manchester (specialists in health measurement and quality of life assessment). It comprised 31 "yes" or "no" questions. Each response indicating lack $\frac{0}{2}$ of wellbeing was scored 1 , giving a score range 0 from 0 to 31, with a high score indicating poor wellbeing. The WISP has been shown to be valid and consistent. ${ }^{17}$ (See appendix 1 for WISP questionnaire.)

Statistics

A paired sample $t$ test was used for within group analyses. Between group analyses were done by $\frac{\tau}{\mathbb{Q}}$ Student's $t$ test in phase 1 , and by one way $\stackrel{?}{+}$ analyses of variance (ANOVA) in phase 2 , using $\frac{0}{0}$ Tukey-Kramer honestly significant difference $\stackrel{\vec{D}}{\vec{D}}$ (HSD) for pairwise comparison. The $\chi^{2}$ good- $\frac{\rho}{\mathbb{D}}$ ness of fit test was used to analyse the difference $\stackrel{D}{\varrho}$ in incidence of complications. Values quoted are mean $(95 \%$ confidence interval given as a 8 single \pm value). In a previous controlled trial examining the efficacy of supplements in

TABLE I Treatment regimens of the four groups of patients

\begin{tabular}{lll}
\hline & Inpatient phase & Outpatient phase \\
\hline Group 1 & Supplements & Supplements \\
Group 2 & Supplements & Control \\
Group 3 & Control & Control \\
Group 4 & Control & Supplements \\
\hline
\end{tabular}


TABLE II Operations performed on the 86 study patients

\begin{tabular}{lll}
\hline & Control & Treatment \\
\hline Right hemicoletomy & 6 & 8 \\
Left hemicolectomy & 2 & 4 \\
Extended right hemicolectomy & 0 & 1 \\
Extended left hemicolectomy & 1 & 0 \\
Transverse colectomy & 1 & 0 \\
Sigmoid colectomy & 4 & 5 \\
Total colectomy & 2 & 1 \\
Panproctocolectomy & 2 & 0 \\
Anterior resection & 8 & 6 \\
Abdominoperineal resection & 4 & 4 \\
Ileoanal pouch & 3 & 2 \\
Gastrectomy: total or subtotal & 6 & 5 \\
Oesophagogastrectomy & 1 & 0 \\
Gastrojejunostomy & 0 & 1 \\
Laparotomy + resection & 1 & 1 \\
Laparotomy + ostomy & 2 & 3 \\
Reversal colostomy & 0 & 2
\end{tabular}

TABLE III Diagnosis of the 86 study patients

\begin{tabular}{lrl}
\hline & Control & Treatment \\
\hline Cancer, colon or rectum & 26 & 26 \\
Cancer, stomach & 7 & 4 \\
Cancer, pancreas & 0 & 1 \\
Inflammatory bowel disease & 7 & 3 \\
Diverticular disease & 1 & 4 \\
Slow transit colon & 2 & 2 \\
Rectovaginal fistula & 0 & 1 \\
Leiomyoma, stomach & 0 & 1 \\
Small bowel lymphoma & 0 & 1 \\
\hline
\end{tabular}

postoperative patients, ${ }^{12}$ we found that a weight loss of $4.7 \mathrm{~kg}$ in control patients was significant at the $5 \%$ level compared with patients randomised to the treatment group. When designing the present trial, calculations showed that 21 patients in each treatment group would be required to achieve a significant difference in weight loss at the $5 \%$ level with a power of $95 \%$. The final numbers in each treatment group were increased, however, to offset overall drop outs which are known to occur in this type of study. ${ }^{12}$

\section{Results}

Phase one

One hundred patients were entered into the study, of whom 53 were randomised on admission to the control group and 47 to the treatment group. Ten subjects were withdrawn from the control group and four from the treatment group for the following reasons. Five control patients could not have the planned operation, one refused to cooperate with the study protocol, and three required parenteral nutrition before study day 1 - that is, before they had started free fluids postoperatively. One control patient required parenteral nutrition on study day 15 . She had an anastomotic breakdown, underwent further surgery on study day 14, and developed a fistula of the small bowel. Her multiple complications were not included in the analysis of complications. Of the four patients withdrawn from the treatment group, two did not undergo the planned operation and two died, both before study day 1 . The deaths were due to myocardial infarction, faecal peritonitis and sepsis.

Patient details - Table II shows the operations performed - the groups were well matched regarding the severity of the operations and underlying diagnosis (Table III). Table IV shows that there were no significant differences in the baseline nutritional variables of the two groups. On admission to the study the patients were margically nutritionally depleted, with a mean weight loss of $4 \% \mathrm{UBW}$ and albumin concentrations at the lower end of the normal range (35-45 g/l). NRI scores indicated mild malnutrition. ${ }^{8}$ Only 12 of the 86 subjects (14\%) had NRI scores below 83.5 , indicating severe malnutrition. Eight of the severely malnourished patients were in the treatment group and four were in the control group. The fatigue scores indicated that patients in each group were slightly tired.

Nutrient intake - Three control patients took oral dietary supplements, having been referred to the ward dietitian with poor nutritional intake. They were not excluded from the control group and the energy and protein contributed by the supplements is included in their daily nutrient intakes. Four patients in the treatment group who refused to take the supplements remained in the supplement group.

Table $\mathrm{V}$ shows the daily nutrient intake of patients during the inpatient phase. Discharge from hospital resulted in the gradual decline in numbers of subjects from study day 1 to study day 7 . There are no significant differences in the nutrient intakes from ward diet between the two groups. However, the treatment group had significantly higher total energy and protein intakes on the first four days of the study period and a significantly higher protein intake on study day 7 .

TABLE IV Nutritional variables and fatigue levels during phase 1

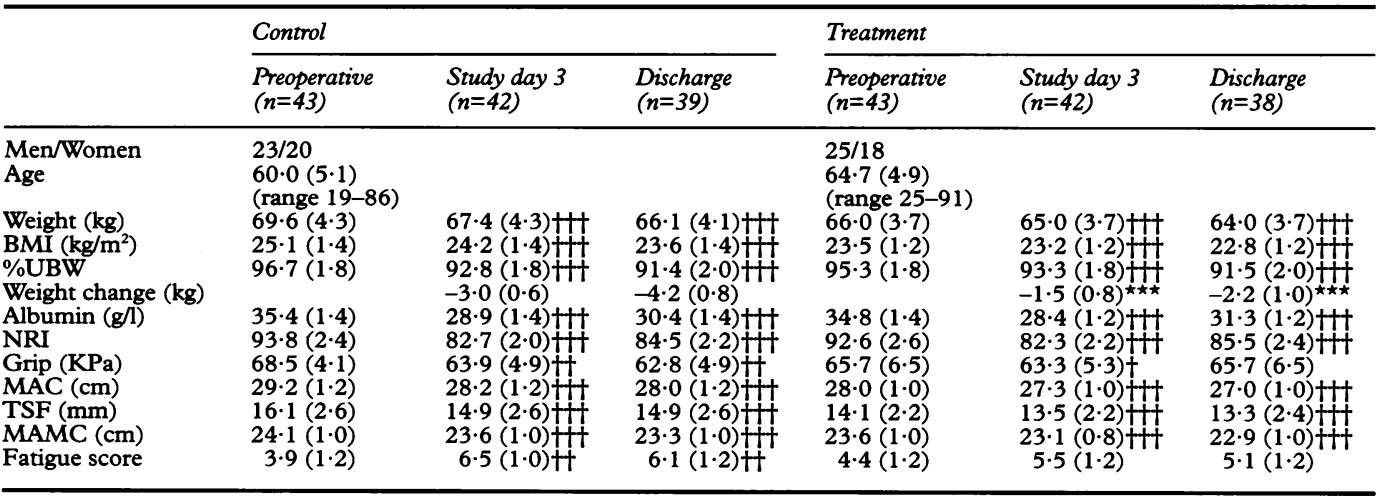

$\star \star \star \mathrm{p}<0.001 v$ control (unpaired $t$ test); $\nmid \mathrm{p}<0.05 ;+\mathrm{p}<0.01 ;++\nmid \mathrm{p}<0.001 v$ preoperative values.

Values are mean $(95 \% \mathrm{CI})$. 
TABLE V Daily nutrient intake of patients during the inpatient phase

\begin{tabular}{|c|c|c|c|c|c|c|c|c|}
\hline \multirow{3}{*}{$\begin{array}{l}\text { Study } \\
\text { period } \\
\text { (days) }\end{array}$} & \multicolumn{3}{|c|}{ Control } & \multicolumn{5}{|c|}{ Treatment } \\
\hline & \multirow[b]{2}{*}{$n$} & \multicolumn{2}{|l|}{ Ward diet } & \multirow[b]{2}{*}{$n$} & \multicolumn{2}{|l|}{ Ward diet } & \multicolumn{2}{|c|}{ Total intake (diet + supplement $)$} \\
\hline & & $\begin{array}{l}\text { Energy } \\
\text { (kcaldday) }\end{array}$ & $\begin{array}{l}\text { Protein } \\
\text { (g/day) }\end{array}$ & & $\begin{array}{l}\text { Energy } \\
\text { (kcallday) }\end{array}$ & $\begin{array}{l}\text { Protein } \\
\text { (g/day) }\end{array}$ & $\begin{array}{l}\text { Energy } \\
\text { (kcalday) }\end{array}$ & $\begin{array}{l}\text { Protein } \\
\text { (g/day) }\end{array}$ \\
\hline $\begin{array}{l}1 \\
1 \\
3 \\
4 \\
5 \\
6 \\
7\end{array}$ & $\begin{array}{l}43 \\
42 \\
40 \\
31 \\
25 \\
17 \\
11\end{array}$ & $\begin{array}{r}480(107 \cdot 8) \\
984(117 \cdot 6) \\
1238(143 \cdot 1) \\
1359(149) \\
1420(203 \cdot 8) \\
1401(266 \cdot 6) \\
1425(329 \cdot 3)\end{array}$ & $\begin{array}{l}13 \cdot 4(3 \cdot 9) \\
31 \cdot 1(4 \cdot 3) \\
41 \cdot 9(4 \cdot 9) \\
46 \cdot 3(5 \cdot 5) \\
48 \cdot 9(7 \cdot 3) \\
47 \cdot 7(8 \cdot 6) \\
45 \cdot 5(10 \cdot 2)\end{array}$ & $\begin{array}{l}43 \\
43 \\
40 \\
27 \\
20 \\
17 \\
12\end{array}$ & $\begin{array}{r}606(113 \cdot 7) \\
1068(133 \cdot 3) \\
1251(129 \cdot 4) \\
1282(166 \cdot 6) \\
1248(139 \cdot 2) \\
1486(178 \cdot 4) \\
1481(154 \cdot 8)\end{array}$ & $\begin{array}{l}19 \cdot 0(4 \cdot 3) \\
34 \cdot 5(4 \cdot 5) \\
45 \cdot 2(4 \cdot 7) \\
43 \cdot 9(5 \cdot 3) \\
44 \cdot 1(7 \cdot 5) \\
48 \cdot 8(8 \cdot 8) \\
53 \cdot 5(9 \cdot 6)\end{array}$ & $\begin{array}{l}878(121 \cdot 5)^{\star \star \star} \\
1366(147)^{\star \star \star} \\
1597(160 \cdot 7)^{\star \star} \\
1627(217 \cdot 6)^{\star} \\
1597(243) \\
1732(192 \cdot 1) \\
1762(213 \cdot 6)\end{array}$ & $\begin{array}{l}28 \cdot 0(4 \cdot 7)^{\star \star \star} \\
45 \cdot 2(5 \cdot 3)^{\star \star \star} \\
56 \cdot 7(5 \cdot 5)^{\star \star \star} \\
55 \cdot 5(6 \cdot 9)^{\star} \\
55 \cdot 2(10 \cdot 6) \\
58 \cdot 7(9 \cdot 4)^{\star} \\
62 \cdot 9(10 \cdot 2)^{\star}\end{array}$ \\
\hline
\end{tabular}

TABLE VI Postoperative course for inpatients

\begin{tabular}{lll}
\hline & Control & Treatment \\
\hline $\begin{array}{l}\text { Duration: } \\
\text { Postoperative nil by } \\
\text { mouth period (days) }\end{array}$ & $5 \cdot 5(0 \cdot 4)$ & $5 \cdot 1(0 \cdot 4)$ \\
$\begin{array}{l}\text { Total postoperative } \\
\text { stay (days) }\end{array}$ & $\begin{array}{l}13 \cdot 2(2 \cdot 6) \\
(\text { median } 11 \cdot 0)\end{array}$ & $\begin{array}{l}10 \cdot 8(1 \cdot 2) \\
(\text { median 10.0) }\end{array}$ \\
$\begin{array}{l}\text { Complications: } \\
\text { Wound infection }\end{array}$ & 7 & 2 \\
$\quad \begin{array}{l}\text { Wound dehiscence } \\
\text { Gastrointestinal perforation }\end{array}$ & 1 & 1 \\
Subphrenic abscess & 1 & 0 \\
$\quad$ Multiple complications & $1 \dagger$ & 0 \\
Total & 12 & $1 \ddagger$ \\
\end{tabular}

Values are mean $(95 \% \mathrm{CI})$ unless stated otherwise.

†Pulmonary emboli, wound dehiscence, and chest infection; fwound infection and chest infection.

${ }^{\star} \mathrm{p}<0.05 v$ control.

Nutritional status and fatigue levels - Table IV shows that there was a general decline in the patients' nutritional status during their hospital stay. Patients in both groups lost weight and serum albumin concentrations fell resulting in a reduction in NRI scores. Anthropometric values dropped in both groups. Control patients lost significantly more weight than treatment patients, both at study day $3(3 \cdot 0$ $(0.59) v 1.5(0.78) \mathrm{kg} ; \mathrm{p}<0.001)$ and discharge $(4 \cdot 2(0 \cdot 78) v 2 \cdot 2(0.98) \mathrm{kg} ; \mathrm{p}<0.001)$. Control patients showed a significant reduction in hand grip strength during their hospital stay. In the treatment group, grip strength dropped at study day 3 , but had returned to preoperative levels by discharge. Fatigue scores in the control group rose from $3.9(1 \cdot 18)$ to 6.5 $(0.98)$ at study day $3,(\mathrm{p}<0.01)$, and $6 \cdot 1(1 \cdot 2)$ at discharge $(p<0 \cdot 01)$. By contrast the treatment group showed a small, non-significant increase in fatigue.

Postoperative course of the inpatients - Table VI shows patients in both groups were nil by mouth for a similar length of time postoperatively, $(5.5(0.4)$ days in controls, $5 \cdot 1$ $(0.4)$ days in the treatment group). The difference in the postoperative duration of stay was not significant. There were 12 complications in the control group and four in the supplement group $(\mathrm{p}<0.05)$.

The patients who developed complications were nil by mouth for a mean of 5.4 days. In one control patient a wound infection developed the day before study day 1 , on the sixth postoperative day. In all other patients complications started between study days 1 and 9 . Wound infections tended to start early - mean study day 3 in the control group (range study $\vec{\circ}$ days $1-8$ ), and on study days 1 and 2 in the two treatment patients. Wound dehiscence $\vec{\omega}$ began on study days 4 and 7 in two control $\widehat{\varrho}$ patients and on study day 8 in a treatment patient. The patient with a gastrointestinal $\stackrel{0}{0}$ perforation underwent surgery on study day $4, \omega$ and the one with a subphrenic abscess had a laparotomy and drainage of the abscess on 0 study day 33 , having had a fluctuating pyrexia since study day 9 .

The control patient with multiple complications developed a chest infection on study $\frac{\hat{\sigma}}{\mathrm{T}}$ day 6 , multiple pulmonary emboli on day $10, \overrightarrow{0}$ and had her wound resutured on day 14. The treatment patient with multiple complications developed a chest infection on study day 1 and a wound infection on study day 5 .

The nutritional status of patients on entry to the study who developed complications (NRI $\stackrel{\varnothing}{\varnothing}$ score $94 \cdot 1(3.5))$ was no different from those $\overrightarrow{\vec{B}}$ who did not (NRI score $93 \cdot 0(2 \cdot 0) ; \mathrm{p}=0 \cdot 6)$.

\section{Phase 2}

Three patients died during the outpatient phase, and four refused to cooperate and were 3 withdrawn.

Nutrient intake - Figures 1 and 2 show the $\frac{\delta}{3}$ patients' energy and protein intakes during 0 phase 2 . One month after discharge there was a significantly higher energy intake in group 1 을 than in groups 2 and $3(p<0.05)$. Two months after discharge group 4 patients had a signifi- or cantly higher intake than patients in group $2 \mathrm{~N}$ $(p<0.05)$. The difference in the protein intakes $\mathrm{N}$ was not significant at any month.

Nutritional status and wellbeing - Sup-co plementation during the outpatient phase had no significant effect on weight, weight change, $\stackrel{+}{+}$ MAC, TSF, MAMC, albumin, grip strength, fatigue levels, or wellbeing.

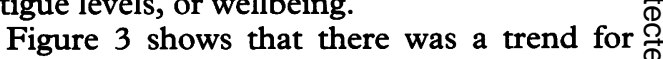
group 1 patients to gain weight most rapidly, $\frac{0}{0}$ but this was not significant.

There was a trend for group 3 patients to 8 have higher wellbeing scores, indicating a lack을 of wellbeing, but the difference was not significant.

\section{Discussion}

We have confirmed that the prescription of oral dietary supplements to inpatients who have undergone elective moderate to major gastrointestinal surgery results in clinically significant 


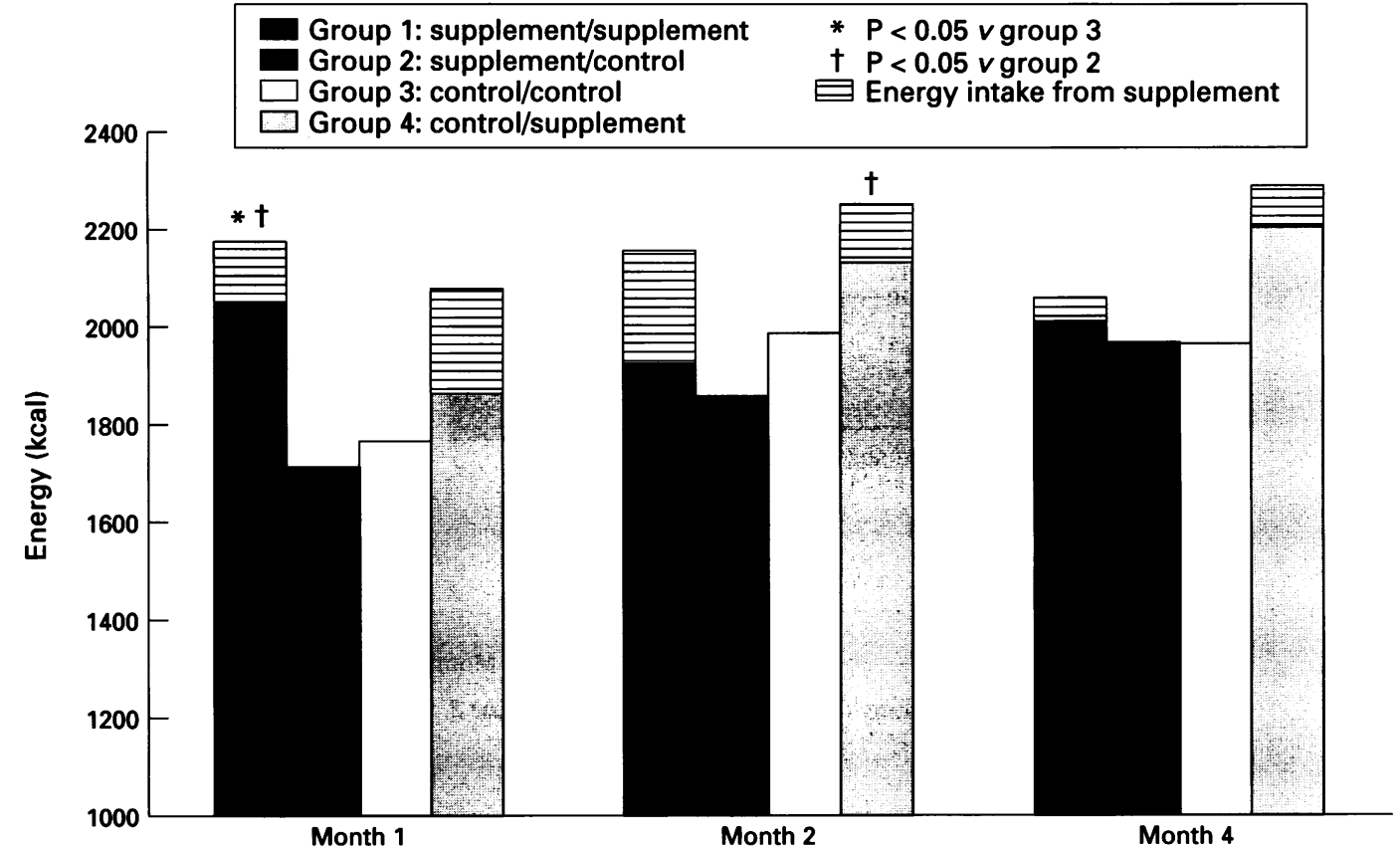

Figure 1: Energy intake during phase 2.

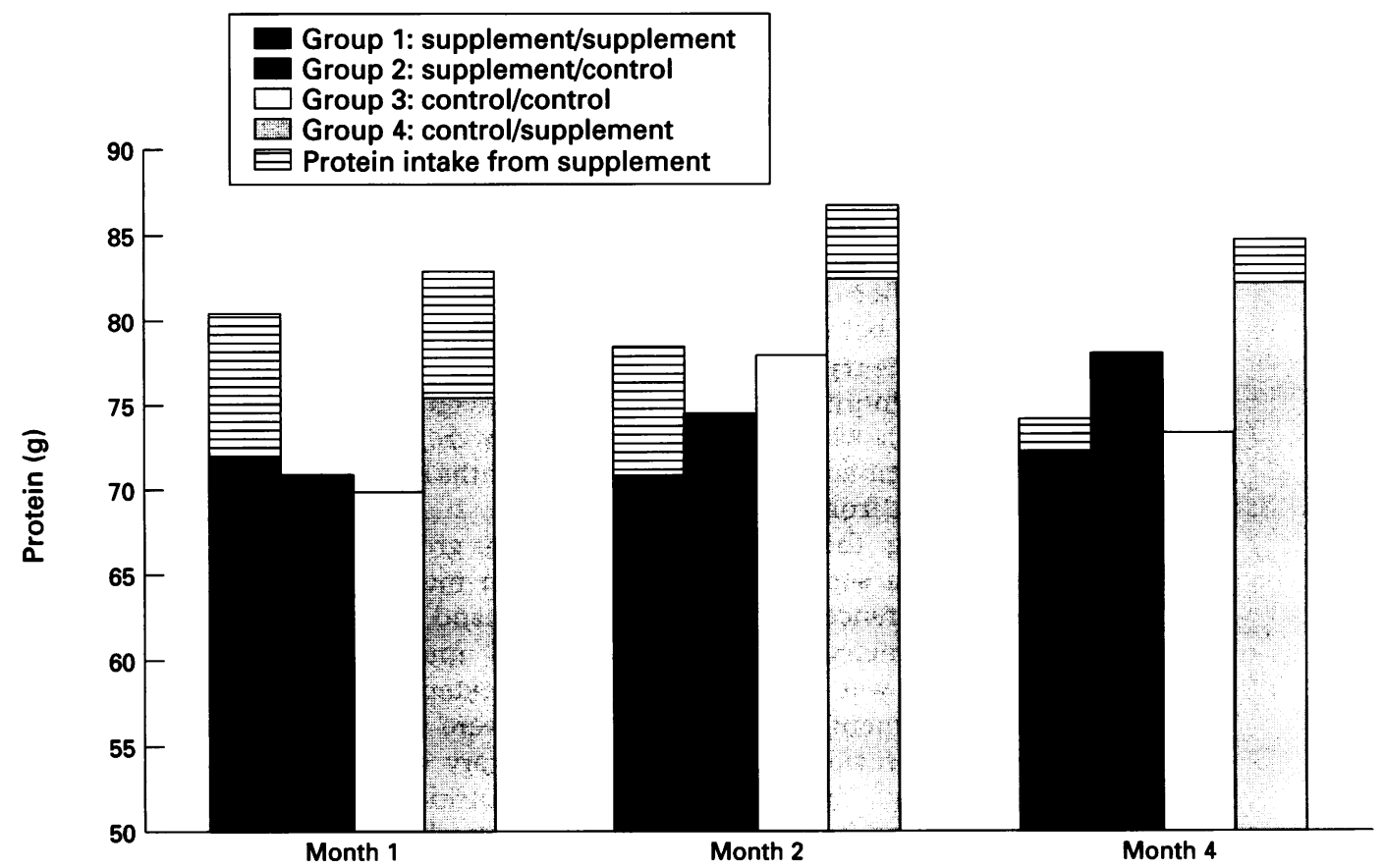

Figure 2: Protein intake during phase 2.

benefits, but have been unable to show benefits of supplementation after discharge from hospital.

During the inpatient phase, energy and protein intakes in both the treatment and control groups remained below estimated requirements for postoperative patients ${ }^{18}$ for their entire hospital stay. These results are in agreement with others. ${ }^{19-21}$ Reasons for a poor nutritional intake are multifactorial. Having undergone surgery to the gastrointestinal tract and a period of starvation, many patients were initially wary of eating solid food. Appetite often did not return fully until after discharge from hospital. In addition the usual problems seen in hospitals of a restricted catering budget, limited meal choices, and meal times imposed by routine contributed to their poor intake. In this study, offering oral dietary supplements to the patients on an ad libitum basis resulted in significant improvements in nutrient intake. As has been previously shown, ${ }^{11} 1222$ giving supplements did not in any way reduce voluntary food intake.

Regardless of whether patients had been taking supplements in hospital, their dietary intake improved over the first month after discharge. Patients in groups 2 and 3 (those not taking supplements during phase 2), had an average intake of about $1700 \mathrm{kcal}$ and $70 \mathrm{~g}$ protein per day, thus easily meeting current recommendations for protein, although their 


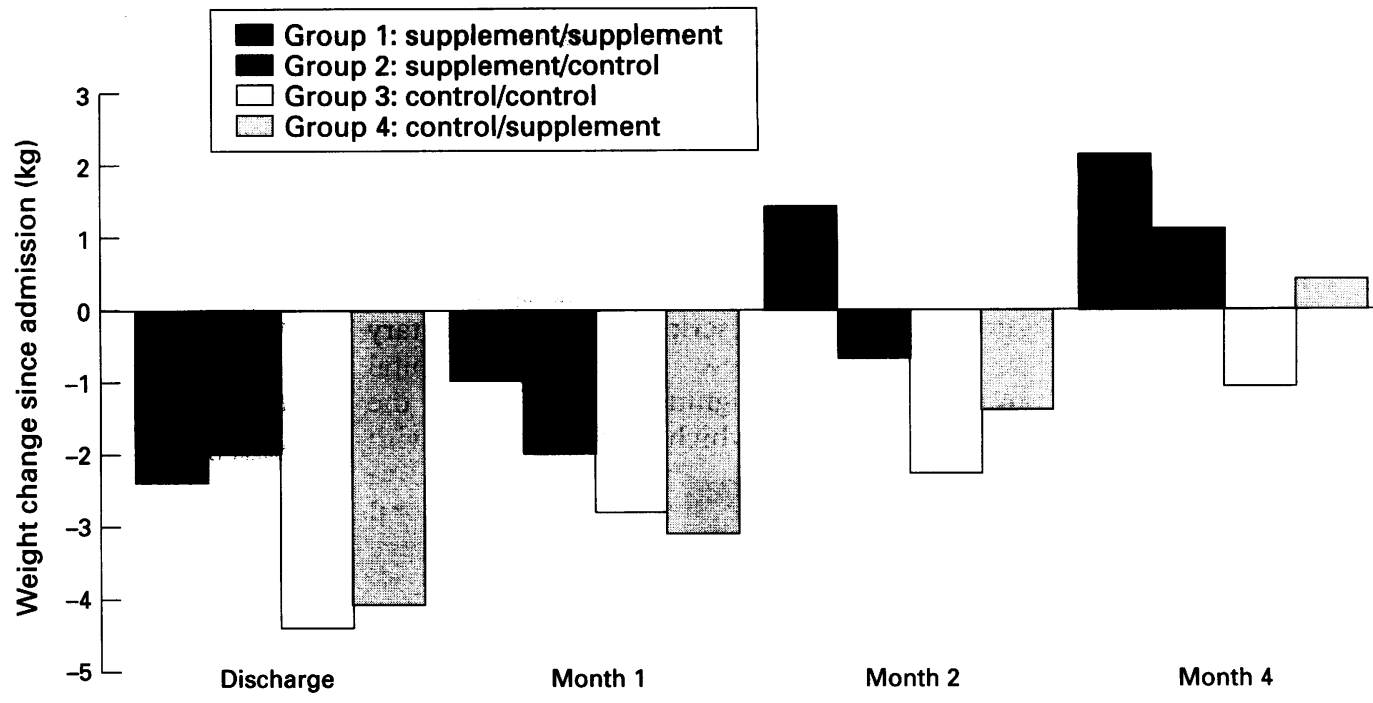

Figure 3: Weight change during phase 1 and phase 2.

energy intakes were a little low. ${ }^{23}$ Patients in group 1 had significantly higher energy intakes one month after discharge than those in groups 2 and 3. It is clear from Figs 1 and 2 that supplements taken at home did not diminish voluntary food intake. The nutrient intake from normal diet tended to be higher in the supplemented patients, although not significant.

Supplemented patients lost significantly less weight during their hospital stay compared with control patients. Figure 3 shows that one month after discharge from hospital all groups were still below their admission weight. Group 1 patients regained their weight most quickly $(1.4 \mathrm{~kg}$ more than their admission weight at month 2), whereas group 3 patients were still below their admission weight four months after discharge from hospital.

During the inpatient phase both groups showed a significant drop in midarm muscle circumference, but the results of the hand grip dynamometry indicate that skeletal muscle function was preserved to a greater extent in the treatment group. Similar effects were seen in our previous study with oral dietary supplements $^{12}$ and rapid effects of nutritional support on hand grip strength have also been shown with parenteral nutrition. ${ }^{24}$ Postoperative fatigue, assessed subjectively by a 10 point analogue scale, developed to a greater extent in the control group compared with the treatment group in the inpatient phase. Other work has shown that increase in fatigue after abdominal surgery correlates with postoperative weight loss. ${ }^{25}$ Both grip strength and fatigue levels had returned to preoperative levels in all groups one month after discharge from hospital.

The most important finding in the inpatient phase was the reduced incidence of postoperative complications in the treatment group - four patients developed complications compared with 12 in the control group $(p<0.05)$. There was a total of nine infectious complications in the control group compared with four in the treatment group. This reduction was similar to that seen in other studies. ${ }^{12}{ }^{26}$ In addition, we have shown a reduction in technical complications; three control patients developed wound dehiscence, compared with $\vec{z}$ only one control patient. The Veterans Affairs TPN Cooperative Study Group showed that $\frac{\hat{\sigma}}{\supset}$ perioperative parenteral nutrition resulted in $\overrightarrow{0}$ reduced complications only in severely malnourished patients $(\mathrm{NRI}<83.5){ }^{8}$ By contrast we have shown that giving an oral dietary supplement resulted in a reduction in serious complications regardless of the preoperative nutritional status of the patients.

It is well established that chronic malnu- $\overrightarrow{\vec{P}}$ trition affects muscle function, ${ }^{27} 28$ immune $\frac{0}{3}$ function, ${ }^{29}$ would healing, ${ }^{30}$ and psychological $\vec{P}$ function, ${ }^{31}$ although the effect of a short period of starvation after surgery is not so clear. Our 0 results indicate that taking supplements postoperatively may have had a beneficial effect on 3 all the above functions. Moreover, the rapidity of the effects suggests a direct action of key $\frac{3}{3}$ nutrients rather than repletion of tissue stores. It may seem surprising that the modest improvement in nutritional intake seen in the study can have such a profound effect, but other studies in which nutritional intake was or improved to a similar extent have also shown 0 dramatic benefits in clinical outcome. ${ }^{11} 1232$

After discharge from hospital it is difficult to 0 find an endpoint that can be measured to 0 determine the patients' recovery. The well- $\frac{D}{\mathbb{D}}$ being index was developed to try to overcome $\stackrel{?}{?}$ this problem. There was no significant $\frac{T}{T}$ difference in the wellbeing scores of the four $\frac{\vec{D}}{\mathbb{D}}$ groups of patients one, two, and four months $\frac{?}{\square}$ after discharge. This is probably because $\varrho$ patients in all groups were eating fairly well and feeling much better by one month after 8 discharge, therefore supplementing their intake had little effect on their wellbeing. It is possible that differences between the groups may have ? been found if the patients had been assessed earlier than one month after discharge, or if more patients had been studied. However, the only conclusion that can be drawn from our outpatient results is that administering nutritional support in the form of oral dietary supplements after discharge from hospital did 
not have a significant effect on the patients' wellbeing.

In conclusion, the results of this study provide no evidence to support the routine prescription of oral dietary supplements to patients who have undergone elective moderate to major gastrointestinal surgery after discharge from hospital. We have, however, shown that the prescription of oral dietary supplements to these patients in hospital results in clinically significant benefits. On the basis of this study, which is in agreement with our earlier work, ${ }^{12}$ we would strongly advocate the routine postoperative prescription of oral dietary supplements to inpatients who have undergone elective moderate to major gastrointestinal surgery.

We are indebted to Mr N Menzies-Gow and Mr M Henry who kindly permitted us to study their patients, and to the surgical house officers and nursing staff for their cooperation during the course of the study. This work was supported by Nutricia Research, Postbus 1, 2700 MA Zoetermeer, Holland.

\section{Appendix 1: WISP questionnaire}

\begin{tabular}{|c|c|c|}
\hline & Yes & No \\
\hline I have plenty of energy & $\square$ & $\square$ \\
\hline On the whole I enjoy life & $\square$ & $\square$ \\
\hline It hurts when I sit too long & $\square$ & $\square$ \\
\hline I often feel nervous & $\square$ & $\square$ \\
\hline I soon lose interest in things & $\square$ & $\square$ \\
\hline It hurts me to go to the toilet & $\square$ & $\square$ \\
\hline I often get depressed & $\square$ & $\square$ \\
\hline I have to be careful what I eat & $\square$ & $\square$ \\
\hline It hurts when I get out of bed & $\square$ & $\square$ \\
\hline I have to sit down a lot & $\square$ & $\square$ \\
\hline I just pick at my food & $\square$ & $\square$ \\
\hline It's an effort to talk to people & $\square$ & $\square$ \\
\hline I sleep well at night & $\square$ & $\square$ \\
\hline I worry about overdoing things & $\square$ & $\square$ \\
\hline I often feel weak & $\square$ & $\square$ \\
\hline I am easily irritated & $\square$ & $\square$ \\
\hline I feel sore inside & $\square$ & $\square$ \\
\hline My bowels give me a lot of problems & $\square$ & $\square$ \\
\hline I wake up feeling tired & $\square$ & $\square$ \\
\hline $\begin{array}{l}\text { I have enough energy for the things I } \\
\text { want to do }\end{array}$ & $\square$ & $\square$ \\
\hline I feel sick when I eat & $\square$ & $\square$ \\
\hline I get discomfort in my stomach & $\square$ & $\square$ \\
\hline I need to lie down during the day & $\square$ & $\square$ \\
\hline I can only eat small meals & $\square$ & $\square$ \\
\hline I'm in pain when I move about & $\square$ & $\square$ \\
\hline I often feel like crying & $\square$ & $\square$ \\
\hline It hurts me when I stand up & $\square$ & $\square$ \\
\hline I often feel bored & $\square$ & $\square$ \\
\hline I'm tired all the time & $\square$ & $\square$ \\
\hline I often feel bloated & $\square$ & $\square$ \\
\hline I have a good appetite & $\square$ & $\square$ \\
\hline
\end{tabular}

Galen Research 1993, for Nutric.

1 Bistrian BR, Blackburn BL, Vitale J, Cochran D, Naylor J Prevalence of malnutrition in general medical patients. fAMA 1976; 235: 1567-70.

2 Hill GL, Blackett RL, Pickford I, Burkinshaw L, Young GA Warren JV, et al. Malnutrition in surgical patients: an unrecognised problem. Lancet 1977; i: 689-92.

3 Bistrian BR, Blackburn BL, Hallowell E, Heddle R. Protein status of general surgical patients. $\mathscr{F A M A} 1974 ; 230$ $858-60$.
$4 \mathrm{McWhirter} \mathrm{J}$, Pennington $\mathrm{CR}$. Incidence and recognition of malnutrition in hospital. $B M 7$ 1994; 308: $945-8$.

5 Dempsey DT, Mullen JL, Buzby GP. The link between nutritional status and clinical outcome: can nutritional intervention modify it? Am f Clin Nutr 1988; 47:352-6.

6 Robinson G, Goldstein M, Levine GM. Impact of nutritional status on DRG length of stay. $\mathcal{f}$ Parenter Enteral Nutr 1987; 11: 49-51.

7 Reilly JJ, Hull SF, Albert N, Waller A, Bringardener S. Economic impact of malnutrition: a model system for hospitalised patients. $\mathcal{F}$ Parenter Enteral Nutr 1988; 12 $371-6$.

8 Veterans Affairs Total Parenteral Nutrition Cooperative Study Group. Perioperative total parenteral nutrition in surgical patients. $N$ Engl f Med 1991; 325: 525-32.

9 McMahon MJ. The feeding jejunostomy. Br $\mathcal{f}$ Clin Prac 1988; 42: 85-8.

10 Sagar S, Harland P, Shields R. Early postoperative feeding with an elemental diet. BMF 1979; 1: 293-5.

11 Delmi M, Rapin CH, Bengoa JM, Delmas PD, Vasey H, Bonjour JP. Dietary supplementation in elderly patients with fractured neck of femur. Lancet 1990; 335: 1013-6.

12 Rana SK, Bray J, Menzies-Gow N, et al. Short term benefits of postoperative oral dietary supplements in surgical patients. Clin Nutr 1992; 11: 337-44.

13 Foodbase nutrition database. The Institute of Brain Chemistry and Human Nutrition, Hackney Hospital, Homerton High Street, London E9 6BE.

14 Jellife DB. The assessment of the nutritional status of the community (with special reference to field studies in developing regions of the world). Geneva: World Health Organisation Monograph Series, 1966; 53: 74-7.

15 Christensen T, Bendix T, Kehlet $H$. Fatigue and cardiorespiratory function following abdominal surgery. $\mathrm{Br} \mathcal{F}$ Surg 1982; 69: 417-9.

16 Buzby GP, Knox LS, Crosby LO, et al. Study protocol: a randomized clinical trial of total parenteral nutrition in malnourished surgical patients. Am f Clin Nutr 1988; 47 366-81.

17 Galen Research. Report prepared on the development and testing of the well-being index for surgical patients (WISP): a measure of postoperative well-being. Manchester: Galen a measure of postop

18 Elia M. Changing concepts of nutrient requirements in disease: implications for artificial nutritional support. Lancet 1995; 345: 1279-84.

19 Hackett AF, Yeung CK, Hill GL. Eating patterns in patients recovering from major surgery - a study of voluntary food intake and energy balance. Br $\mathcal{F}$ Surg 1979; 66: 415-8.

20 Todd EA, Hunt P, Crowe PJ, Royle GT. What do patients eat in hospital? Human Nutrition - Applied Nutrition 1984; 38: 294-7.

21 Meguid MM, Mughal MM, Debonis D, Meguid V, Terz JJ. Influence of nutritional status on the resumption of adequate food intake in patients recovering from colorectal cancer operations. Surg Clin North Am 1986; 66: 1167-76.

22 Woo J, Ho SC, Mak YT, Law LK, Cheung A. Nutritional status of elderly patients during recovery from chest infection and the role of nutritional supplementation assessed by a prospective randomised single-blind trial. Age Ageing 1984; 23: 40-8.

23 Panel on Dietary Reference Values of the Committee on Medical Aspects of Food Policy. Dietary reference values for food and energy and nutrients for the United Kingdom. for food and energy and nutrients for the United Kingdom.
Report of the Panel on Dietary Reference Values on the Committee on Medical Aspects of Food Policy. London Department of Health Report on Health and Social Subjects, HMSO, 1991

24 Christie PM, Hill GL. Effect of intravenous nutrition on nutrition and function in acute attacks of inflammatory bowel disease. Gastroenterology 1990; 99: 730-6.

25 Christensen $T$, Kehlet $H$. Postoperative fatigue and changes in nutritional status. Br 7 Surg 1984; 71: 473-6.

26 Carr CS, Ling KDE, Boulous $P$, Singer $M$. Randomized trial of safety and efficacy of immediate postoperative enteral feeding in patients undergoing gastrointestinal resection. $B M \mathscr{F}$ 1996; 312: 869-71.

27 Arora NS, Rochester DF. Respiratory muscle strength and maximal voluntary ventilation in undernourished patients. Am Rev Respir Dis 1982; 126: 5-8.

28 Lopes J, Russell DMCR, Whitwell J, Jeejeebhoy KN. Skeletal muscle function in malnutrion. Am f Clin Nutr 1982; 36: $602-10$.

29 Chandra RK, Newberne PM. Nutrition, immunity and infection. Mechanisms of interactions. New York: Plenum Press, 1977.

30 Haydock DA, Hill GL. Improved wound healing response in surgical patients receiving intra-venous nutrition. $\mathrm{Br} \mathcal{F}$ Surg 1987; 74: 320-3

31 Brozek J. Effects of generalised malnutrition on personality. Nutrition 1990; 6: 389-95.

32 Larsson J, Unosson M, Ek AC, Nilsson L, Thorslund S, Bjurulf P. Effect of dietary supplement on nutrional status and clinical outcome in 501 geriatric patients randomised study. Clin Nutr 1990; 9: 179-84. 